\title{
Soil Suitability Evalution for Plantation Crops in Wanci Island, Wakatobi Regency, Indonesia
}

\author{
M.Tufaila ${ }^{1, *}$, La ode Rustam ${ }^{1}$, Hasbullah Syaf ${ }^{1}$, Made Widana Arsana ${ }^{2}$, \\ La Ode Afa ${ }^{2}$, Nini Mila Rahni ${ }^{2}$, Awaluddin Hamzah ${ }^{3}$, Jufri Karim ${ }^{4}$ \\ ${ }^{I}$ Department of Soil Science Faculty of Agriculture, University of Halu Oleo, Kendari, Indonesia \\ ${ }^{2}$ Department of Agrotechnology Faculty of Agriculture, University of Halu Oleo, Kendari, Indonesia \\ ${ }^{3}$ Department of Agribusiness Faculty of Agriculture, University of Halu Oleo, Kendari, Indonesia \\ ${ }^{4}$ Department of Geography Faculty of Earth Sciences and Technology, University of Halu Oleo, Kendari, Indonesia \\ *Corresponding author. Email: m.tufailahemon@yahoo.go.id
}

\begin{abstract}
The Island of Wanci consists of unproductive lands whose area continuously increases, and therefore, integrated planning is required. A 4-month soil suitability evaluation for plantation crops was carried out in the District of South Wangi-Wangi using a structured survey method with an inter grid distance of $500 \mathrm{~m}$. The results of soil observations per grid were mapped and resulted in 49 land units. Data of climate, soil physics and chemistry in each land unit were matched with land suitability criteria for several plantation crops, i.e. clove, durian, cashew, cocoa, coffee, coconut, mango, banana, rambutan dan salak crops. Land suitability class evaluation was based on soil actual and potential conditions. The results of the study showed that (1) Based on the actual soil conditions, all land units in the study area $(6.065,08 \mathrm{ha})$ were not suitable $(\mathrm{N})$ for the cultivation of those aforementioned crops; (2) Based on the potential soil conditions, the study area fell into 2 soil suitability classes, i.e. marginally suitable (S3) and not suitable (N). Only $19.4 \%$ of the study area $(1.178,01 \mathrm{ha})$ was marginally suitable, while the rest $(80.6 \%$ or $4.887,07$ ha) was not suitable; (3) The dominant limiting factors in the study area were low rainfall (wa), rapid permeability (oa), shallow soil depth (rc), erosion hazard (eh) and constraints for land preparation due to surface rocks and rock outcrops (lp). Based on the results, it could be recommended that crop cultivations within the study area be conducted only on the marginally suitable land units. Such areas need further research on optimum fertilizer application and method in order for the crops to grow and produce better.
\end{abstract}

Keywords: plantation crops, land suitability evaluation, Wanci

\section{INTRODUCTION}

Wanci island is one of the small islands within the administrative region of Wakatobi Regency. Located to the southeast of Buton Island, it is dominated by limestone parent material, coral type, with relatively level topography, and with Entisol and Inceptisol as the most dominant soil types [1]. The infertile soil causes the land to be covered mainly by forest trees and shrubs. This condition causes the unproductive land to continuously increase every year. In addition, the area for crop cultivations is limited because most lands in Wanci Island are within protected forest areas.

Because of the current infertile land conditions plus the limited area for crop cultivations, a detailed survey needs to be carried out to assess the land actual and potential conditions. The survey aimed to assess the actual and potential land suitability for plantation crops in the District of Wangi-Wangi Selatan, Wanci Island. It is expected that the study could be used for a land suitability-based development of plantation crops in the study area in order for the crops to grow and produce better and more sustainably.

\section{METHODS}

The study was conducted in the District of Wangi-Wangi Selatan, Regency of Wakatobi, Southeast Sulawesi, for 4 months from August to November, 2018. The method used was the structured survey [2] with an intergrid distance of $500 \mathrm{~m}$. The results of land observations per grid were mapped resulting in 49 land units. After having been overlaid against the protected forest area map [3], 10 land units were obtained for plantation-crop suitability evaluation. Data of climate (e.g. annual rainfall and temperature), soil physics (e.g. drainage, soil texture, coarse materials, effective soil depth, erosion hazard, and surface rocks), and soil chemistry (e.g. cation exchange capacity, clay, base saturation, $\mathrm{pH}$, and organic-C) were gathered from field observations and laboratory analysis. The data of each land unit were matched against the land suitability criteria for 10 plantation crops, i.e. clove, durian, cashew, 
cocoa, coffee, coconut, mango, banana, rambutan and salak crops.

The land suitability analysis was conducted based on the actual land conditions and on the potential land conditions after soil improvements had been applied. The assessment was done by matching land characteristics against crop growth requirements [4]. The matching approach produced 4 land suitability classes, i.e. suitable (S1), moderately suitable (S2), marginally suitable (S3), and not suitable (N). The results were presented in a form of land suitability map in which distribution, area covered, and constraints for plantation-crop cultivations in the study area.

\section{RESULTS AND DISCUSSION}

\section{A. General Overview of the Study Area}

The District of Wangi-Wangi Selatan is located in the southern region of Wanci Island, covering an area of $12,145.55$ ha from $123^{\circ} 27^{\prime}$ to $123^{\circ} 39^{\prime} \mathrm{E}$ and from $05^{\circ} 16^{\prime}$ to $05^{\circ} 27^{\prime} \mathrm{S}$. Its topography is mostly $(88.69 \%)$ with elevations ranging from 0 to $30 \mathrm{~m}$ above sea level. The district is mostly flat (88.69\%) with slope gradients ranging from 0 to $3 \%$, followed by $41-60 \%$ slope (10.02\%), and $8-15 \%$ slope $(1.29 \%)$ [1].

Parent materials in the study area are dominated (89.98\%) by Buara Formation with coral, conglomerate, and sandy rock type. The rest $(10.02 \%)$ is covered by Sampolakosa Formation with rock type of Napal and Calcarenite. Soil types are dominated by Udhorthents and Eutrudepts [1].

Data of climate in the study area were gathered from Betoambari weather station. The average annual rainfall was $1,729.7$ (P. $75 \%=1,315.9 \mathrm{~mm})$ with 134 days of rainfalls. The average monthly rainfalls ranged from 244.34 $\mathrm{mm}(\mathrm{P} .75 \%=184.50 \mathrm{~mm})$ to $2.94 \mathrm{~mm}(\mathrm{P} .75 \%=18.45$ $\mathrm{mm}$ ). The highest rainfall occurred in May consisting of 17 days of rainfalls, while the lowest occurred in September consisting of only 5 days of rainfalls. Based on the Schmidt-Fergusson climate classification [5], where a wet month is when rainfall exceeds $100 \mathrm{~mm} \mathrm{month}^{-1}$ and a dry month is when rainfall is less than $60 \mathrm{~mm} \mathrm{month}^{-1}$, the climate in the study area fell under climate type $\mathrm{C}$ because it had 4 wet months and 8 dry months. In other words, the study area had a climate type of somewhat dry. The average temperature in the study area in 2018 ranged from $21.30^{\circ} \mathrm{C}$ to $34.50^{\circ} \mathrm{C}$, while its air humidity and speed was $76 \%$ and $3.18 \mathrm{~m} \mathrm{~s}^{-1}$, respectively.

Data of climate in the study area were gathered from Betoambari weather station. The average annual rainfall was $1,729.7$ (P. $75 \%=1,315.9 \mathrm{~mm}$ ) with 134 days of rainfalls. The average monthly rainfalls ranged from 244.34 $\mathrm{mm}(\mathrm{P} .75 \%=184.50 \mathrm{~mm})$ to $2.94 \mathrm{~mm}(\mathrm{P} .75 \%=18.45$ $\mathrm{mm})$. The highest rainfall occurred in May consisting of 17 days of rainfalls, while the lowest occurred in September consisting of only 5 days of rainfalls. Based on the Schmidt-Fergusson climate classification [5], where a wet month is when rainfall exceeds $100 \mathrm{~mm} \mathrm{month}^{-1}$ and a dry month is when rainfall is less than $60 \mathrm{~mm} \mathrm{month}^{-1}$, the climate in the study area fell under climate type $\mathrm{C}$ because it had 4 wet months and 8 dry months. In other words, the study area had a climate type of somewhat dry. The average temperature in the study area in 2018 ranged from $21.30^{\circ} \mathrm{C}$ to $34.50^{\circ} \mathrm{C}$, while its air humidity and speed was $76 \%$ and $3.18 \mathrm{~m} \mathrm{~s}^{-1}$, respectively.

\section{B. Actual Land Suitability Evaluation}

The actual land suitability for plantation crops in the study area was obtained by matching the land characteristics against the crop growth requirements. The crops evaluated were clove, durian, cashew, cocoa, coffee, coconut, mango, banana, rambutan and salak. The results of the actual land suitability for plantation crops are presented in Table 1, while their spatial distributions are presented in Figure 1.

Table 1. The actual land suitability classes for plantation-crops in the study area

\begin{tabular}{|c|c|c|c|c|c|c|c|c|c|c|c|}
\hline \multirow{2}{*}{$\begin{array}{l}\text { Land } \\
\text { Unit }\end{array}$} & \multicolumn{10}{|c|}{ The actual land suitability for plantation crops } & \multirow{2}{*}{$\begin{array}{c}\text { Area } \\
\text { (ha) }\end{array}$} \\
\hline & Clove & Durian & Cashew & Cocoa & Coffee & Coconut & Mango & Banana & $\begin{array}{c}\text { Rambut } \\
\text { an }\end{array}$ & Salak & \\
\hline 1 & Noa.rc & Noa.rc & Noa.rc & Noa.rc & Noa.rc & Noa.rc & Noa.rc & Noa.rc & Noa.rc & Noa.rc & 29.24 \\
\hline 2 & Noa.rc.lp & Noa.rc.lp & Noa.rc.lp & Noa.rc.lp & Noa.rc.lp & Noa.rc.lp & Noa.rc.lp & Noa.rc.lp & Noa.rc.lp & Noa.rc.lp & 15.62 \\
\hline 3 & Noa.rc & Noa.rc & Noa.rc & Noa.rc & Noa.rc & Noa.rc & Noa.rc & Noa.rc & Noa.rc & Noa.rc & 14.92 \\
\hline 4 & Noa.rc & Noa.rc & Noa.rc & Noa.rc & Noa.rc & Noa.rc & Noa.rc & Noa.rc & Noa.rc & Noa.rc & $1,130.89$ \\
\hline 5 & Noa.rc.lp & Noa.rc.lp & Noa.rc.lp & Noa.rc.lp & Noa.rc.lp & Noa.rc.lp & Noa.rc.lp & Noa.rc.lp & Noa.rc.lp & Noa.rc.lp & 867.17 \\
\hline 6 & Noa.rc.lp & Noa.rc.lp & Noa.rc.lp & Noa.rc.lp & Noa.rc.lp & Noa.rc.lp & Noa.rc.lp & Noa.rc.lp & Noa.rc.lp & Noa.rc.lp & $1,350.79$ \\
\hline 7 & Neh & Neh & Neh & Neh & Neh & Neh & Neh & Neh & Neh & Neh & 353.02 \\
\hline 8 & Neh & Neh & Neh & Neh & Neh & Neh & Neh & Neh & Neh & Neh & $2,164.16$ \\
\hline 9 & Nrc.eh & Nrc.eh & Nrc.eh & Nrc.eh & Nrc.eh & Nrc.eh & Nrc.eh & Nrc.eh & Nrc.eh & Nrc.eh & 96.53 \\
\hline 10 & Neh & Neh & Neh & Neh & Neh & Neh & Neh & Neh & Neh & Neh & 42.74 \\
\hline \multicolumn{11}{|c|}{ Total area (ha) } & 6.065 .08 \\
\hline
\end{tabular}

$\mathrm{oa}=$ oxygen avibility, $\mathrm{rc}=$ root condition, $\mathrm{lp}=$ land preparation, $\mathrm{eh}=$ erosion hazard. 

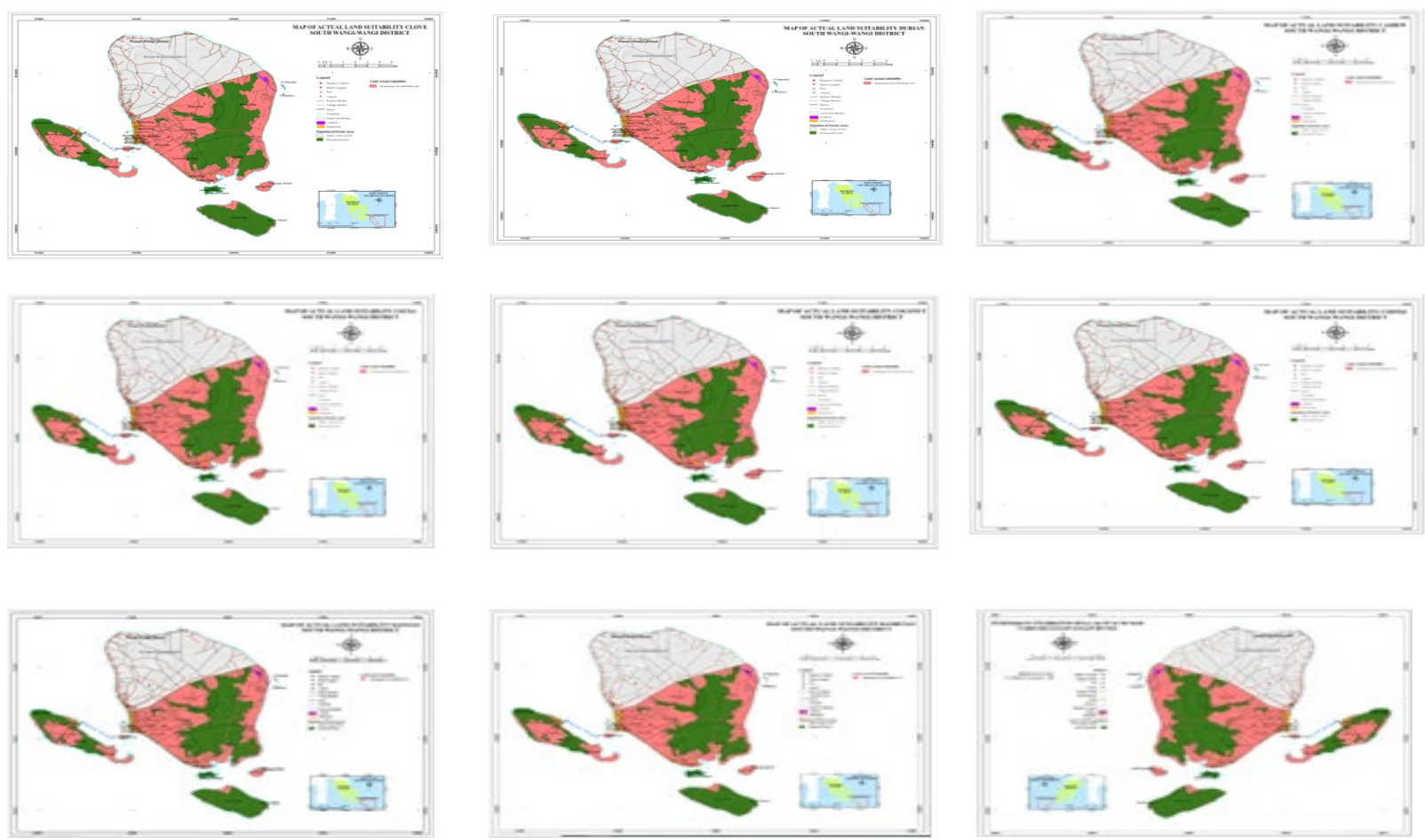

Figure 1. Distribution of actual land suitability classes for plantation crops in the study area

Table 1 shows that the actual land suitability classes for plantation crops in the study area consist of class $\mathrm{N}$ (not suitable) with different limiting factors on several groups of land units. Limiting factors of oa, $\mathrm{rc}$ and $\mathrm{lp}$ were found in land unit 2, 5 and 6 covering an area of 2,235.58 ha; limiting factors of oa and $\mathrm{rc}$ in land unit 1,3, and 4

\section{Potential Land Suitability Evaluation}

Potential land suitability for plantation crops in the study area was conducted by increasing the actual land suitability classes one level. The increased land suitability was done covering an area of 1,175.05 ha; and a limiting factor of eh was found in land unit 7,8 and 10 covering an area of $2,559.92$ ha. These indicate that a total area of 6,065.08 ha is actually not suitable for the cultivation of clove, durian, cashew, cocoa, coffee, coconut, mango, banana, rambutan, and salak crops.

by improving and mitigating the lowest limiting factors by the matching approach against the lowest limiting factors [4]. The results of the potential land suitability for plantation crops are presented in Table 2, while their spatial distributions are presented in Figure 2.

Table 2. The potential land suitability classes for plantation-crops in the study area

\begin{tabular}{|c|c|c|c|c|c|c|c|c|c|c|c|}
\hline \multirow{2}{*}{$\begin{array}{c}\text { Land } \\
\text { Unit }\end{array}$} & \multicolumn{10}{|c|}{ The potential land suitability for plantation crops } & \multirow{2}{*}{$\begin{array}{c}\text { Area } \\
\text { (ha) }\end{array}$} \\
\hline & Clove & Durian & Cashew & Cocoa & Coffee & Coconut & Mango & Banana & Rambutan & Salak & \\
\hline 1 & Noa.rc & Noa.rc & Noa.rc & Noa.rc & Noa.rc & Noa.rc & Noa.rc & Noa.rc & Noa.rc & Noa.rc & 29.24 \\
\hline 2 & Noa.rc.lp & Noa.rc.lp & Noa.rc.lp & Noa.rc.lp & Noa.rc.lp & Noa.rc.lp & Noa.rc.lp & Noa.rc.lp & Noa.rc.lp & Noa.rc.lp & 15.62 \\
\hline 3 & Noa.rc & Noa.rc & Noa.rc & Noa.rc & Noa.rc & Noa.rc & Noa.rc & Noa.rc & Noa.rc & Noa.rc & 14.92 \\
\hline 4 & Noa.rc & Noa.rc & Noa.rc & Noa.rc & Noa.rc & Noa.rc & Noa.rc & Noa.rc & Noa.rc & Noa.rc & $1,130.89$ \\
\hline 5 & Noa.rc.lp & Noa.rc.lp & Noa.rc.lp & Noa.rc.lp & Noa.rc.lp & Noa.rc.lp & Noa.rc.lp & Noa.rc.lp & Noa.rc.lp & Noa.rc.lp & 867.17 \\
\hline 6 & Noa.rc.lp & Noa.rc.lp & Noa.rc.lp & Noa.rc.lp & Noa.rc.lp & Noa.rc.lp & Noa.rc.lp & Noa.rc.lp & Noa.rc.lp & Noa.rc.lp & $1,350.79$ \\
\hline 7 & S3rc.eh & S3rc.nr.eh & S3rc.nr.eh & S3rc.nr.eh & S3rc.nr.eh & S3rc.nr.eh & S3rc.nr.eh & S3rc.nr.eh & S3rc.eh & S3rc.nr.eh & 353.02 \\
\hline 8 & S3rc.eh & S3rc.nr.eh & S3rc.nr.eh & S3rc.nr.eh & S3rc.nr.eh & S3rc.nr.eh & S3rc.nr.eh & S3rc.nr.eh & S3rc.eh & S3rc.nr.eh & $2,164.16$ \\
\hline 9 & Nrc.eh & Nrc.eh & Nrc.eh & Nrc.eh & Nrc.eh & Nrc.eh & Nrc.eh & Nrc.eh & Nrc.eh & Nrc.eh & 96.53 \\
\hline 10 & S3rc.eh & S3rc.nr.eh & S3rc.nr.eh & S3rc.nr.eh & S3rc.nr.eh & S3rc.eh & S3rc.nr.eh & S3rc.nr.eh & S3rc.nr.eh & S3rc.nr.eh & 42.74 \\
\hline \multicolumn{11}{|c|}{ Total area (ha) } & 6.065 .08 \\
\hline
\end{tabular}

$\mathrm{oa}=$ oxygen avibility, $\mathrm{rc}=$ root condition, $\mathrm{lp}=$ land preparation, $\mathrm{eh}=$ erosion hazard. 

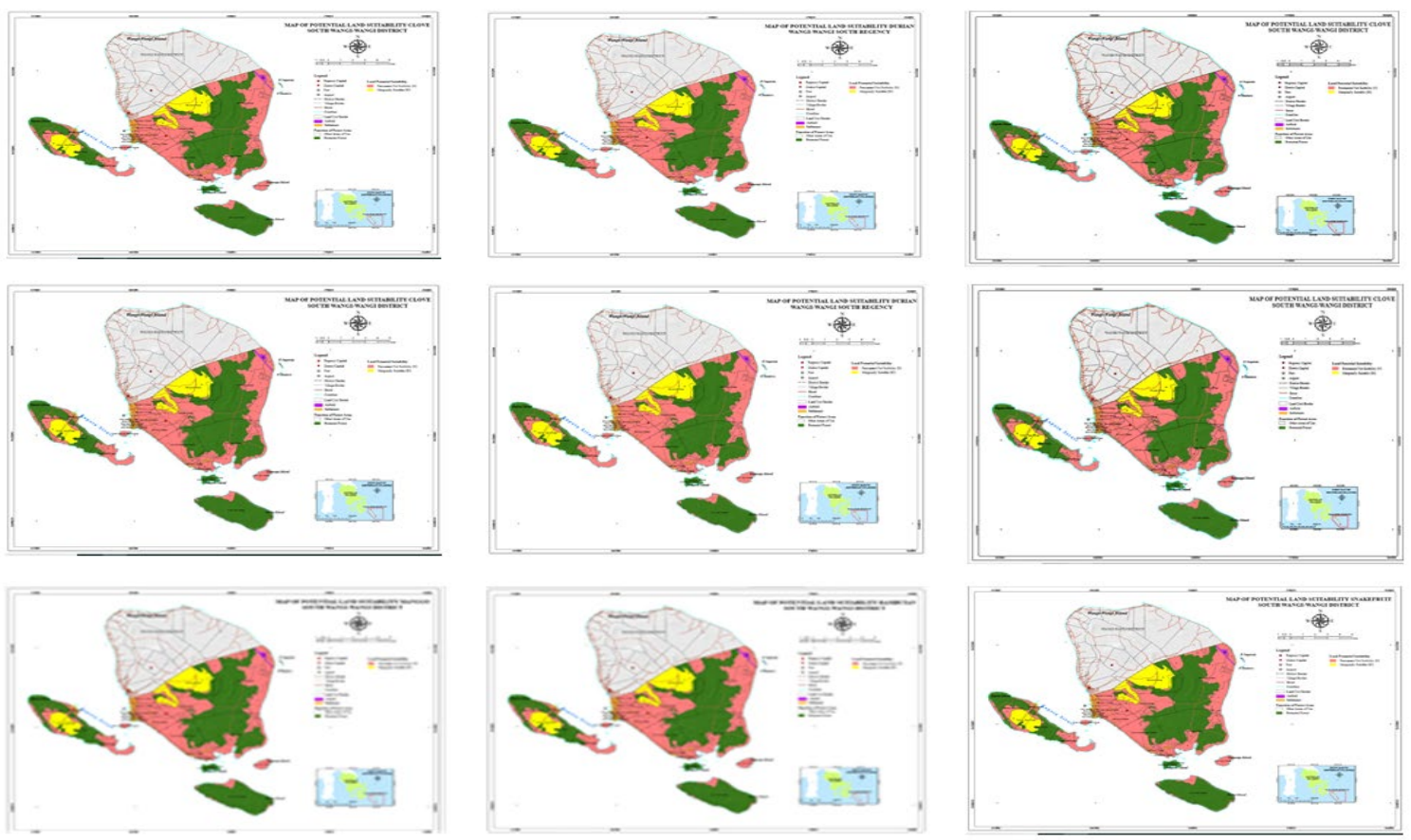

Figure 2. Distribution of potential land suitability classes for plantation crops in the study area

Table 2 shows that the potential land suitability classes for plantation crops in the study area fell into 2 soil suitability classes, i.e. marginally suitable (S3) and not suitable (N). Only $19.4 \%$ of the study area $(1,178.01$ ha) was marginally suitable, while the rest $(80.6 \%$ or $4.887,07$ ha) was not suitable. The limiting factors in not-suitable land units for the cultivation of clove, durian, cashew, cocoa, coffee, coconut, mango, banana, rambutan, and salak crops were oa, rc and lp (in land unit 2, 5 and 6 covering an area

\section{CONCLUSION}

The conclusions of the current study are (1) Based on the actual soil conditions, all land units in the District of Wangi-Wangi Selatan $(6,065.08$ ha) were not suitable $(\mathrm{N})$ for the cultivation of clove, durian, cashew, cocoa, coffee, coconut, mango, banana, rambutan dan salak crops; (2) Based on the potential soil conditions, the district fell into 2 soil suitability classes, i.e. marginally suitable (S3) and not suitable $(\mathrm{N})$. Only $19.4 \%$ of the study area $(1,178.01 \mathrm{ha})$ was marginally suitable, while the rest $(80.6 \%$ or $4.887,07$ ha) was not suitable; (3) The dominant limiting factors in the study area were low rainfall (wa), rapid permeability (oa), shallow soil depth (rc), erosion hazard (eh) and constraints for land preparation due to surface rocks and rock outcrops (lp). Based on the results, it could be recommended that crop cultivations within the District of Wangi-Wangi Selatan be conducted only on the marginally suitable land units. Such areas, however, need further research on optimum fertilizer applications and effective cultivation methods in order for the crops to grow and produce better. of 2,235.58 ha), and oa and rc (in land unit 1,3, and 4 covering an area of 1,175.05 ha). Since the marginally potential land suitability for the cultivation of those crops were only found in land unit $7,8,9$, and 10 , the cultivation of those crops should be done in those 4 land units. Moreover, further research especially on optimum fertilizer applications and effective cultivation methods needs to be done in order for the crops to grow and produce better.

\section{ACKNOWLEDGMENT}

We would like to express our gratitude to Bappeda, Wakatobi Regency for the financial support because of which the study could be done as planned.

\section{REFERENCES}

[1] M. Tufaila, H. Syaf, J. Karim, L. Rustam, Laporan evaluasi kesesuaian lahan tanaman pangan dan perkebunan di Kecamatan Wangi-Wangi Selatan. Kerjasama Bappeda Wakatobi dan Fakultas Pertanian Universitas Halu Oleo, 2018

[2] P. V. Marsden \& J. D. Wright, Handbook of survey research. Bingley, England: Emerald, 2010

[3] Biphut Sultra, Peta penetapan kawasan hutan Sultra, Kendari, Sulawesi Tenggara, 2013

[4] D. Djaenudin, H. Marwan, H. Subagjo, and A. Hidayat, Petunjuk teknis evaluasi lahan untuk komoditas pertanian. Balai Besar Litbang Sumberdaya Lahan Pertanian, Badan Litbang Pertanian, Bogor. 36p., 2011.

[5] F. H. Schmidt and J. H. A. Ferguson, Rainfall type based on wet and dry period ratio for Indonesia with Western New Gurinea. Kementerian Perhubungan, 1951. 